\title{
Análise dos Processos de Desmatamento e Regeneração nas Unidades de Conservação Pertencentes no Vale do Ribeira (SP/PR) por Meio de Classificações de Imagens de Sensoriamento Remoto
}

\author{
Analysis of Deforestation and Regeneration Processes in Conservations Units Belong to \\ Ribeira Valley - SP/PR, Brazil Through Sensing Remote Images Classifications
}

Amanda Lopes Maciel ${ }^{1}$, Diógenes Alves ${ }^{2}$, Sidnei Sant'Anna ${ }^{3}$

1 Instituto Nacional de Pesquisas Espaciais, Divisão de Processamento de Imagens, São José dos Campos-SP, Brasil. Email: amandamaciel.eng@gmail.com.

ORCID: https://orcid.org/0000-0002-7398-0658

2 Instituto Nacional de Pesquisas Espaciais, Divisão de Processamento de Imagens, São José dos Campos-SP, Brasil. Email: dalves@dpi.inpe.br.

ORCID: https://orcid.org/0000-0003-0559-0671

3 Instituto Nacional de Pesquisas Espaciais, Divisão de Processamento de Imagens, São José dos Campos-SP, Brasil. Email: sidnei.santanna@inpe.br.

ORCID: https://orcid.org/0000-0001-7557-3215

Resumo: O Vale do Ribeira, situado entre dois importantes estados do Brasil: São Paulo e Paraná, detém cerca de 80\% dos remanescentes contínuos de Mata Atlântica. Diversos fatores físicos e históricos permitiram a conservação desses remanescentes na região. Destacam-se entre eles a topografia, baixa fertilidade dos solos e o regime hídrico como substanciais para preservação da vegetação natural, além da criação de Unidades de Conservação (UCs). Entretanto, estudos têm apontado históricos de desmatamento em tais áreas. Em reconhecimento à importância de relacionar os processos responsáveis pelas mudanças do uso da terra, utilizam-se técnicas de sensoriamento remoto no intuito de investigar a associação de mudanças à cobertura florestal. Este trabalho teve como objetivo identificar e mapear as áreas de regeneração e desmatamento nos limites das UCs do Vale do Ribeira (SP/PR) em uma série temporal de 1985 a 2017, comparando os resultados em relação à toda região. Considerando-se a distribuição das coberturas florestais dentro das UCs, a regeneração florestal representou cerca de $30 \%$ do ganho líquido florestal total, enquanto o processo de desmatamento foi em torno de 22\%. Com exceção de APA Quilombos do Médio Ribeira, APA Serra do Mar, PE do Turvo e RDS Barreiro Anhemas, as UCs apresentaram aproximadamente desmatamento zero. Por outro lado, foram nessas mesmas áreas em que se calcularam os maiores ganhos florestais por regeneração. Conclui-se que a criação das UCs é sim importante para o decréscimo das taxas de desmatamento e favorecimento da preservação florestal do bioma, aliada às operações de fiscalização.

Palavras-chave: Análise multitemporal. Imagens Landsat. Dinâmica de processos florestais. Fiscalização.

\begin{abstract}
The Ribeira Valley, localized between two important states of Brazil: São Paulo and Paraná, presents approximately $80 \%$ of the most preserved remnants of Atlantic Forest. Several physics and histories factors allowed the conservation of these remnants in this region. The topography, low soil fertility and water regime stand out as great allies for preservation of natural vegetation, in addition to the creation of Conservation Units. However, studies have pointed deforestation history in those protection areas. In order to relate the responsible processes for land-use changes, sensing remote techniques have been used in intention to investigate forest cover changes association. This work claimed to identify and map regeneration and deforestation areas in limits of Ribeira Valley's Conservation Units in temporal serie from 1985 to 2017, comparing the results related to all region. Considering the forests covers distribution in Conservation Units, the forestall regeneration represented about $30 \%$ of total net gain, while the deforestation process was approximately 22\% from 1985 to 2017. With exception of APA Quilombos do Médio Ribeira, APA Serra do Mar, PE Turvo and RDS Barreiro Anhemas, others Conservation Units had approximately zero deforestation. On the other hand, those areas were the same that forest gain calculated by regeneration were the biggest. Concludes that the creation of Conservation Units is important indeed to deforestation decrease range and favoring the forestal preservation of biome, allied the inspection actions.
\end{abstract}

Keywords: Multitemporal analysis. Landsat Images. Dynamics of forest processes. Inspection. 


\section{INTRODUÇÃO}

O bioma Mata Atlântica ocupa cerca de $15 \%$ do território nacional e concentra-se em locais onde se incidem $72 \%$ da população em 17 estados brasileiros. Em razão do seu contexto histórico de ocupação, em grande parte, devido às expansões agrícolas, os remanescentes do bioma representam pouco mais de $10 \%$ de sua cobertura original (RIBEIRO et al., 2009; FUNDAÇÃO SOS MATA ATLÂNTICA/INPE, 2019).

A maior parte dos remanescentes florestais em áreas contínuas e conservadas do bioma Mata Atlântica está localizada no Vale do Ribeira (MINISTÉRIO DO MEIO AMBIENTE, 2010), localizado entre os Estados de São Paulo e Paraná. Cerca de 6\% da área das Unidades de Conservação (UCs) do bioma está localizada no Estado de São Paulo (FUNDAÇÃO SOS MATA ATLÂNTICA/INPE, 2017). Dentro da extensão territorial do Vale do Ribeira, mais da metade da área está inserida em um sistema de proteção ambiental, criando um grande cinturão de proteção a biodiversidade e ao patrimônio cultural, histórico, espeleológico, arqueológico e arquitetônico do país (ALVES, 2004; MUNARI, 2009; RIBEIRO FILHO, 2015; SOUZA, 2017).

Fatores físicos e históricos permitiram a conservação desses remanescentes na região. Destacam-se, entre eles, a topografia, baixa fertilidade dos solos e o regime hídrico como determinantes para a preservação da vegetação natural, além da criação de áreas protegidas, como as UCs (INSTITUTO AGRONÔMICO DE CAMPINAS, 1990; RESENDE, 2011). De acordo com o Sistema Nacional de Unidades de Conservação (SNUC - Lei $n^{\circ}$ 9.985/2000; BRASIL, 2006), Unidades de Conservação são definidas como "espaços territoriais e seus recursos ambientais, incluindo as águas jurisdicionais, com características naturais relevantes, legalmente instituídos pelo Poder Público, com objetivos de conservação e limites definidos, sob regime especial de administração, ao qual se aplicam garantias adequadas de proteção.".

Por outro lado, a região presencia muitos conflitos ambientais, nos quais atividades de conservação têm sido responsabilizadas pelo subdesenvolvimento econômico e social da região, sendo vista até como um fator limitante para isso (REZENDE, 2011). Tendo em vista que as atividades agrícolas são a principal fonte de renda para o Vale do Ribeira, as próprias comunidades locais, ao terem que lidar com as Unidades de Conservação, as enxergam como entraves, na medida que restringem suas formas de uso tradicional da terra (SILVA, 2013).

Neste caso, a agricultura em pequena escala é uma prática comum nas UCs no bioma Mata Atlântica (SANTOS et al., 2016). Por isso, os sistemas agroflorestais se apresentam como uma possibilidade promissora, à medida que propiciam o restabelecimento de processos ecológicos e a produção de alimentos simultaneamente, além de aumentar a biodiversidade local e poder gerar progressiva autonomia para produção, consumo e renda da família agricultora (PALUDO; COSTABEBER, 2012). Apesar da nítida vocação florestal e em sentido oposto à sustentabilidade, as principais atividades econômicas desenvolvidas na região do Vale do Ribeira são as monoculturas de banana, pupunha e eucalipto e a exploração predatória dos recursos florestais, como madeira e palmito de juçara (FAVRETO, 2010).

Com a finalidade de investigar associações relacionadas aos processos florestais, como desmatamento e regeneração florestal, o uso de dados de sensoriamento remoto proporciona uma alternativa para analisar questões relacionadas às mudanças de uso e cobertura da terra, bem como contribui para o monitoramento de áreas de interesses diversas (DEVRIES et al., 2015). Ou seja, pode-se dizer que o monitoramento ambiental é uma ferramenta útil e de grande importância para o planejamento territorial derivado da análise multitemporal via classificação de imagens de sensoriamento remoto (TORRES, 2011; CASTILLO et al., 2015).

Diversos trabalhados tem estudado fatores associados às mudanças florestais ocorrentes dentro do bioma Mata Atlântica, tais como Ferreira et al. (2015), Silva et al. (2016), Costa et al. (2017), Rezende et al. (2018) e Duarte (2019). Nesse contexto, o uso das imagens classificadas para várias datas permite identificar por exemplo, áreas que sofreram mudanças na cobertura da terra, como a derrubada de uma floresta ou o abandono de um cultivo e posterior regeneração florestal (FUNDAÇÃO SOS MATA ATLÂNTICA/INPE, 2019; TEIXEIRA et al., 2019).

Desse modo, este estudo teve como objetivo localizar os processos de desmatamento e regeneração nas Unidades de Conservação no Vale do Ribeira (SP/PR), sob perspectiva de uma análise temporal das mudanças de uso e cobertura da terra na região no período de 1985 a 2017, utilizando imagens de média resolução espacial $(30 \mathrm{~m})$ dos satélites Landsat 5 e 8 . Para este presente estudo, considera-se regeneração 
florestal a reconstituição natural e espontânea de um ecossistema degradado em razão a processos de sucessão florestal, enquanto desmatamento é a retirada total ou parcial de qualquer tipo de cobertura vegetal (ARONSON et al., 2011; EMPRESA BRASILEIRA DE PESQUISA AGROPECUÁRIA, 2012).

\section{2 ÁREA DE ESTUDO}

O estudo realizou-se no Vale do Ribeira, compreendendo a cena ponto-órbita 220/077, pois recobria a maioria dos municípios da região. A região do Vale é localizada ao sul do Estado de São Paulo e a leste do Estado do Paraná, e sua área de 2.830,66 km² abriga uma população de 481.224 habitantes (SISTEMA DE INFORMAÇÕES TERRITORIAIS, 2015). A Figura 1 demostra os trinta municípios pertencentes ao Vale do Ribeira, sendo sete paranaenses e vinte e três paulistas.

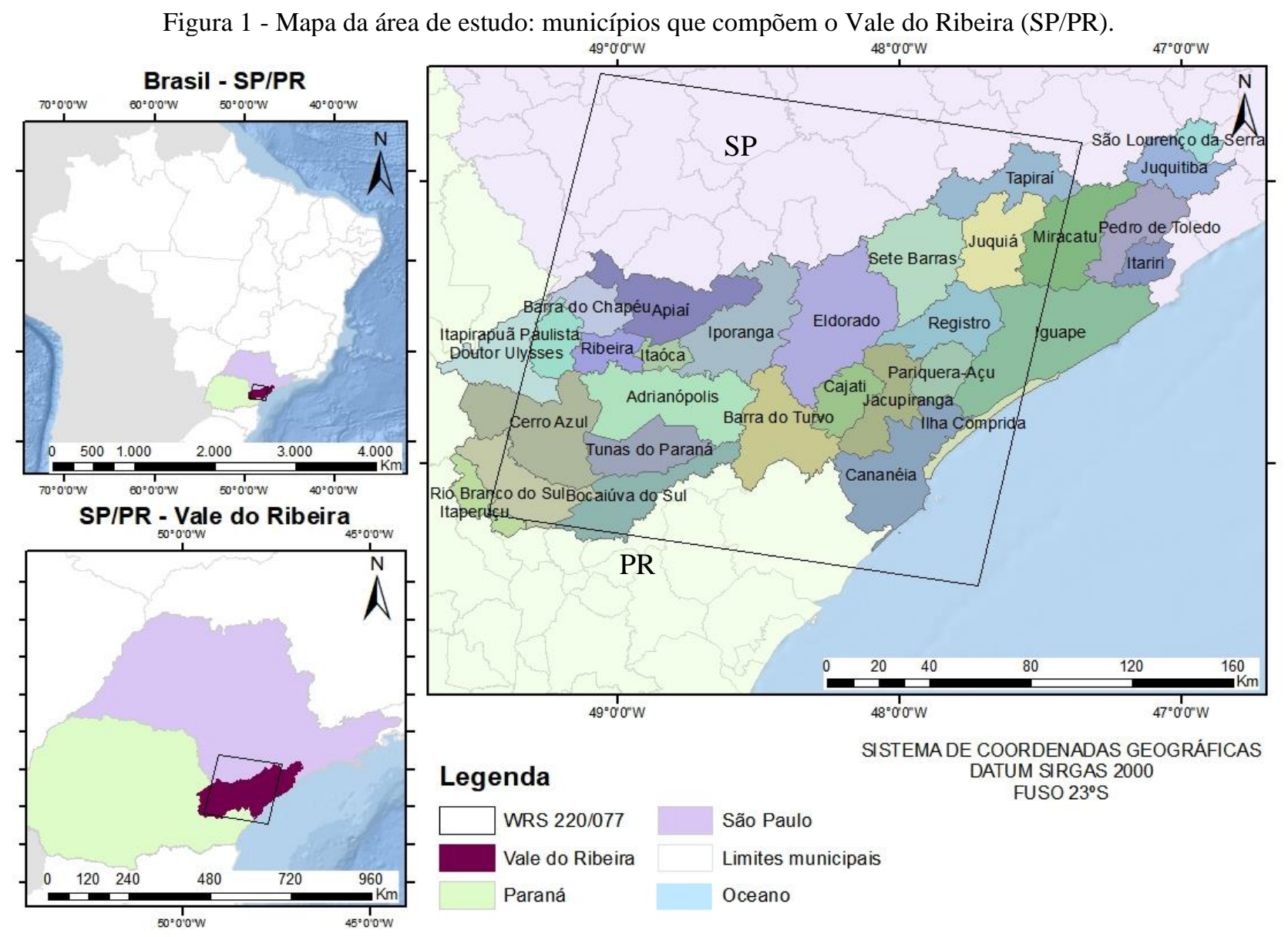

Fonte: Os autores (2021).

Com relação à caracterização geológica regional, o Vale do Ribeira está inserido na Faixa Dobrada Apiaí, compondo o segmento sudoeste do Cinturão Ribeira (COMITÊ DA BACIA HIDROGRÁFICA DO RIO RIBEIRA DE IGUAPE E LITORAL SUL, 2016). A região encontra-se sobre o flanco sudeste da Serra de Paranapiacaba, com altitudes que variam de 0 (nível do mar) a 1.845 metros (MACIEL, 2020).

O solo do Vale do Ribeira é predominantemente argiloso, e pouco permeável, de forma que armazena bastante água, mas não é eficiente no recarregamento do aquífero (CBH-RB, 2016). A área de estudo se caracteriza pelo clima tropical úmido, sendo tropical úmido sem estação seca em $5 \%$ da bacia hidrográfica Ribeira de Iguape e Litoral Sul, subtropical úmido com verão quente em $50 \%$ da bacia e subtropical úmido com verão fresco em 45\%, segundo a classificação a classificação de Köppen (CBH-RB, 2018). A região apresenta alta precipitação anual média $(1.400 \mathrm{~mm} / \mathrm{ano})$, e a temperatura média anual é de $20^{\circ} \mathrm{C}$, com média mínima de $14^{\circ} \mathrm{C}$ e máxima de $27^{\circ} \mathrm{C}(\mathrm{CBH}-\mathrm{RB}, 2016)$.

A bacia hidrográfica Ribeira do Iguape e Litoral Sul é denominada bacia de conservação devido à elevada disponibilidade hídrica de boa qualidade, à pequena demanda de uso e ao baixo potencial de poluição 
(SISTEMA INTEGRADO DE GERENCIAMENTO DE RECURSOS HÍDRICOS DO ESTADO DE SÃO PAULO, 2020). A cobertura vegetal natural é da ordem de $80 \%$, apresentando cerca $12.256 \mathrm{~km}^{2}$ de vegetação natural remanescente, distribuídas nas principais categorias Floresta Ombrófila Densa e a Formação Arbórea/Arbustiva em Região de Várzea (SIGRH, 2020).

Embora cerca de $6 \%$ da extensão territorial das Unidades de Conservação municipais dentro do bioma Mata Atlântica estão concentradas no Estado de São Paulo (FUNDAÇÃO SOS MATA ATLÂNTICA/INPE, 2017), em relação ao limite territorial do Vale do Ribeira, existem 45 Unidades no total, definidas e geridas pelos Estados de São Paulo e Paraná (SIGRH, 2020; MMA, 2020). Entretanto, foram identificadas 27 UCs dentro da área de estudo (Figura 2) e suas respectivas informações são constatadas na Tabela 1.

Figura 2 - Unidades de Conservação localizadas dentro da área de estudo.

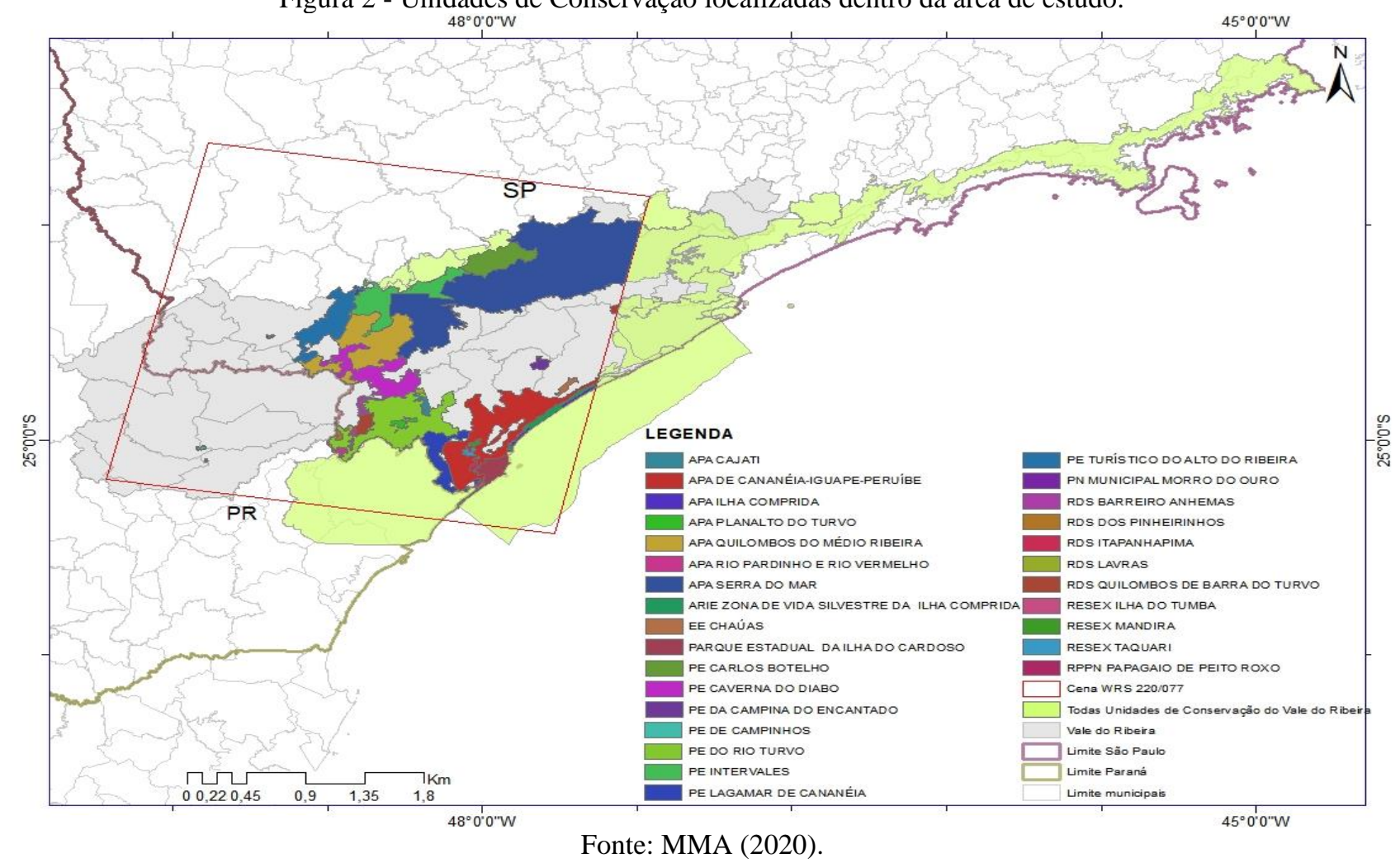

Tabela 1 - Unidades de Conservação dentro da área de estudo. Legenda: APA- Área de Proteção Ambiental; EEEstação Ecológica; PE- Parque Estadual; PN- Parque Nacional; RDS- Reserva de Desenvolvimento Sustentável; RESEX- Reserva Extrativista; RPPN- Reserva Particular de Patrimônio Natural; US- Uso Sustentável; PI- Proteção

\begin{tabular}{|c|c|c|c|c|c|c|}
\hline \multicolumn{7}{|c|}{ Integral. } \\
\hline & Nome & Grupo & Esfera & Estado & Ano de criação & Extensão $\left(\mathrm{km}^{2}\right)$ \\
\hline 1 & APA Cajati & US & Estadual & SP & 2008 & 29,75 \\
\hline 2 & APA de Cananéia-Iguape-Peruíbe & US & Federal & SP & 1984 & 2023,10 \\
\hline 3 & APA Ilha Comprida & US & Estadual & SP & 1987 & 192,09 \\
\hline 4 & APA Planalto do Turvo & US & Estadual & SP & 2008 & 0,02 \\
\hline 5 & APA Quilombos do Médio Ribeira & US & Estadual & SP & 2008 & 0,64 \\
\hline 6 & APA Rio Pardinho e Rio Vermelho & US & Estadual & SP & 2008 & 0,03 \\
\hline 7 & APA Serra do Mar & US & Estadual & SP & 1984 & 670,00 \\
\hline 8 & EE Chaúas & PI & Estadual & SP & 1978 & 26,99 \\
\hline 9 & PE da Ilha do Cardoso & PI & Estadual & SP & 1962 & 131,60 \\
\hline 10 & PE Carlos Botelho & PI & Estadual & SP & 1982 & 376,40 \\
\hline 11 & PE Caverna do Diabo & PI & Estadual & SP & 2008 & 400,00 \\
\hline 12 & PE da Campina do Encantado & PI & Estadual & SP & 1994 & 23,60 \\
\hline 13 & PE de Campinhos & PI & Estadual & PR & 1960 & 3,37 \\
\hline 14 & PE do Rio Turvo & PI & Estadual & SP & 2008 & 738,20 \\
\hline & PE Intervales & PI & Estadual & SP & 1995 & 406,50 \\
\hline & PE Lagamar de Cananéia & PI & Estadual & SP & 2008 & 406,60 \\
\hline & PE Turístico do Alto do Ribeira & PI & Estadual & SP & 1958 & 0,36 \\
\hline
\end{tabular}




\begin{tabular}{ll|c|c|c|r|r} 
(Conclusão) \\
\hline & Nome & Grupo & Esfera & Estado & Ano de criação & Extensão $\left(\mathrm{km}^{2}\right)$ \\
\hline 18 & PN Municipal Morro do Ouro & PI & Municipal & SP & 2004 & 4,02 \\
19 & RDS Barreiro Anhemas & US & Estadual & SP & 2008 & 0,03 \\
20 & RDS dos Pinheirinhos & US & Estadual & SP & 2008 & 15,30 \\
21 & RDS Itapanhapima & US & Estadual & SP & 2008 & 0,01 \\
22 & RDS Lavras & US & Estadual & SP & 2008 & 8,90 \\
23 & RDS Quilombos de Barra do Turvo & US & Estadual & SP & 2008 & 0,05 \\
24 & RESEX Ilha do Tumba & US & Estadual & SP & 2008 & 0,01 \\
25 & RESEX Mandira & US & Federal & SP & 2002 & 1,75 \\
26 & RESEX Taquari & US & Estadual & SP & 2008 & 16,62 \\
27 & RPPN Papagaio de Peito Roxo & US & Federal & PR & 2017 & \\
\hline
\end{tabular}

Fonte: MMA (2020).

Segundo o Sistema Nacional de Unidades de Conservação (SNUC) (2006), nas unidades de uso sustentável (US) é permitida a exploração dos recursos naturais de forma controlada, de forma a conciliar a conservação da natureza com o uso sustentável dos recursos. Protege a área e permite ocupação humana. Dentre elas destacam-se as Áreas de Proteção Ambiental (APAs), as Reservas de Desenvolvimento Sustentável (RDS), as Reservas Particular de Patrimônio Natural (RPPN) e as Reservas Extrativista (RESEX). Com relação às unidades de Proteção Integral (PI), as regras e normas são mais restritivas, não permitindo a ocupação humana. Neste grupo é permitido apenas o uso indireto dos recursos naturais e é aberto para realização de pesquisas e educação ambiental. São estações ecológicas, parques nacionais e estaduais. (BRASIL, 2006).

\section{MATERIAL E MÉTODOS}

Para este estudo, foram utilizadas quatro imagens dos sensores Thematic Mapper (TM) (anos 1985, 1995 e 2006) e Operational Land Imager (OLI) (ano 2017), referente, respectivamente, aos satélites Landsat5 e Landsat-8. As imagens são disponíveis no acervo digital do United States Geological Survey (USGS) em: https://earthexplorer.usgs.gov/. A escolha se deve pelo fato de que as imagens de ambos sensores satisfazem o objetivo do estudo.

As imagens apresentam valores de reflectância de superfície, alusivas ao produto Landsat Surface Reflectance. Essas têm projeção Universal Tranverse Mercator (UTM), Sistema de Referência WGS84 e resolução espacial de 30 metros. As cenas foram selecionadas pelos autores deste trabalho, sempre que possível, em períodos de menor cobertura de nuvens, compreendido entre abril e setembro, visto que a vegetação apresentaria alta resposta espectral por ser o período subsequente à estação chuvosa (PONZONI, 2001; PONZONI, SHIMABUKURO, 2010).

Mesmo tendo a preocupação com os métodos de seleção das imagens, teve a necessidade de realização de recortes de diversas imagens Landsat adquiridas no acervo do USGS, de mesma data ou próxima, com as partes das cenas que não tiveram interferências atmosféricas (presença de nuvens) ou ruídos, para se obter as quatros imagens completas visualmente boa que cobrisse toda a área de estudo para os anos de 1985, 1995, 2006 e 2017. Desse modo, essas imagens formadas foram utilizadas como entrada para a aplicação do classificador.

Feito isso, as composições foram feitas associando cada imagem a um canal, as quais foram escolhidas mediante a realização de testes com o objetivo de diferenciar visualmente com alto contraste espectral as classes de cobertura florestal. Considerando tais informações, optou-se por RGB453 para todas imagens do sensor TM e RGB564, para as do sensor OLI como as mais adequadas.

As imagens foram classificadas utilizando um classificador supervisionado Compound Maximum Likelihood (REIS et al., 2017a). Este algoritmo foi utilizado porque considera um conjunto de imagens da série temporal para realização da classificação baseado na probabilidade de ocorrência das transições entre pares de classes, evitando assim, a classificação de transições impossíveis (REIS et al., 2017a). Considera-se uma transição impossível como algo que nunca poderia acontecer dado o intervalo de tempo, como uma área urbana se regenerar.

Segundo seus criadores, a primeira etapa da aplicação do algoritmo se refere ao cálculo automático das probabilidades de ocorrência de cada classe pixel a pixel para cada imagem baseado nas amostras 
adquiridas na etapa anterior e serviu de entrada para a segunda parte do código. A segunda parte de aplicação do algoritmo consiste no cálculo dos pesos e das transições possíveis entre as classes de anos sequentes em análise. Por fim, a terceira parte do código consiste na classificação resultante das imagens e a análise de acurácia do classificador (REIS et al., 2017a).

Para realizar o mapa de cobertura florestal, foram definidas quatro classes principais, as quais foram:

- Remanescentes de Mata Atlântica (REM): vegetação de porte arbóreo maduro de floresta nativa da Mata Atlântica, de fisionomias vegetais de floresta ombrófila densa e formações pioneiras do bioma, como mangue e restinga;

○ Regeneração (REG): vegetação de porte arbóreo, em estágio inicial, médio ou não avançado, pós evento de degradação ambiental, ou seja, florestas sucessionais;

- Reflorestamento (REF): vegetação plantada para fins comerciais ou recuperação de áreas degradadas, como eucalipto e pinus; e

○ Não-floresta (NF): discriminação de áreas não florestais, como perímetro urbano, corpo d'água, mosaico de agricultura, cultivo agrícola e pastagem, reunidas apenas no final da edição dos mapas.

Os resultados da classificação automática foram utilizados como dado de entrada para análises dos processos florestais (regeneração e desmatamento) na área de estudo estruturado no software ArcGIS 10.4. Para verificação da classificação, foram empregadas imagens do Google Earth, devido à sua resolução espacial de $1 \mathrm{~m}$, visando o maior detalhamento possível da região. Para tal, utilizou-se a ferramenta linha do tempo, a fim de comparar se cada imagem temática foi satisfatória e condizente com a realidade apresentada nas imagens que compõem o acervo da plataforma, pesquisando àquelas de anos iguais ou próximas, sempre que possível.

Para a validação das imagens temáticas, foram estimados o Índice Kappa e a Exatidão Global para cada ano de classificação, sobrepondo um conjunto de 200 amostras de referência aleatórias e diferentes para cada ano analisado de área $4 \mathrm{~km}^{2}$ feitas por interpretação visual das imagens do Google Earth e extração do mesmo conjunto de amostras referente ao mapa gerado de cobertura florestal para o ano em análise. Foi gerada a matriz de confusão, com os erros de omissão e comissão computados utilizando o software ENVI.

Após realizada a álgebra de mapas entre os mapas de cobertura florestal e cada ano para analisar a dinâmica de mudança florestal da região, foram analisados os fragmentos de remanescentes e regeneração espacialmente, no que tange a inclusão às principais áreas protegidas. Para isso, do acervo do Ministério do Meio Ambiente (MMA) foi utilizado o mapa temático das UCs federais, estaduais e municipais, disponível em https://www.mma.gov.br/areas-protegidas/cadastro-nacional-de-ucs/dados-georreferenciados.html em formato shapefile. Vinte e sete Unidades de Conservação dentro da área de estudo (cena ponto-órbita 220/077) foram identificadas. Os dados referentes à área de cada UC foram exportados para o programa de computador Excel®, e por meio da criação de tabela dinâmica e cálculos realizados, obteve-se os resultados do desmatamento e regeneração da área total e em cada UC.

\section{RESULTADOS}

A respeito da confiabilidade dos mapas apresentados, a matriz de confusão para 1985 é apresentada na Tabela 2, incluindo os erros de omissão e comissão. O coeficiente Kappa estimado para o mapa de cobertura florestal para o ano de 1995 foi de 0,80. A Exatidão Global de 89,94\% está dentro do patamar estabelecido por Jensen (1986), de 85\%. A maior porcentagem do erro de comissão no mapa de 1985 ocorreu na classe REG $(16,75 \%)$, o que pode estar relacionado à confusão espectral entre a classe de cobertura florestal REM, principalmente. O maior erro de omissão também ocorreu na classe REG (30,41\%), em que grande parte dos pixels foi classificada como REM (26,14\%), o que significa que cerca de $30 \%$ dos pixels de toda a região não foram devidamente classificados como regeneração. A classe que apresentou os menores erros de comissão foi REF (3,86\%) e a classe com menores erros de omissão foi REM (3,87\%), expressando que quase todos os pixels verdadeiramente pertencentes a essa classe foram rotulados corretamente. 
Tabela 2 - Matriz de Confusão da classificação e Índice de Concordância Kappa da classificação de cobertura florestal

\begin{tabular}{|c|c|c|c|c|c|c|c|c|}
\hline \multirow{2}{*}{\multicolumn{2}{|c|}{ Classes }} & \multirow[b]{2}{*}{ REM } & \multicolumn{3}{|c|}{ Referência } & & \multirow{2}{*}{\multicolumn{2}{|c|}{ Erro de comissão (\%) }} \\
\hline & & & NF & REF & REG & TOTAL & & \\
\hline \multirow{5}{*}{ 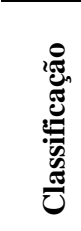 } & REM & 563686 & 24435 & 9872 & 25853 & 623846 & 9,64 & \\
\hline & $\mathrm{NF}$ & 9229 & 129339 & 1096 & 3540 & 143204 & 9,68 & \\
\hline & REF & 733 & 85 & 37520 & 688 & 39026 & 3,86 & \\
\hline & REG & 12742 & 584 & 522 & 68837 & 82685 & 16,75 & \\
\hline & TOTAL & 586390 & 154443 & 49010 & 98918 & 888761 & - & \\
\hline \multirow{3}{*}{\multicolumn{2}{|c|}{ Erro de omissão (\%) }} & 3,87 & 16,25 & 23,44 & 30,41 & - & - & \\
\hline & & & & & & \multirow{2}{*}{\multicolumn{2}{|c|}{ Exatidão Global: }} & $89,94 \%$ \\
\hline & & & & & & & & $\hat{k}: \quad 0,80$ \\
\hline \multirow{2}{*}{\multicolumn{2}{|c|}{ Matriz de confusão (\%) }} & \multicolumn{5}{|c|}{ Referência } & & \\
\hline & & REM & NF & REF & REG & & & \\
\hline \multirow{4}{*}{ 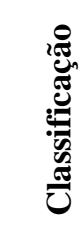 } & REM & 96,13 & 15,82 & 20,14 & 26,14 & & & \\
\hline & $\mathrm{NF}$ & 1,57 & 83,75 & 2,24 & 3,58 & & & \\
\hline & REF & 0,13 & 0,06 & 76,56 & 0,70 & & & \\
\hline & REG & 2,17 & 0,38 & 1,07 & 69,59 & & & \\
\hline
\end{tabular}
Fonte: Os autores (2021).

Para o mapa de 1995, a Exatidão Global foi $90,24 \%$ e o Kappa estimado foi equivalente a 0,80. A matriz de confusão e os erros de comissão e omissão podem ser observados na Tabela 3. Pode-se observar que o erro de comissão foi maior para a classe REG (17,78\%), em que houve maior confusão com a classe REM $(2,08 \%)$, o que também pode ser explicado pelas semelhanças espectrais entre essas classes. A classe com maior erro de omissão também foi REG $(29,11 \%)$, em que grande parte dos pixels foi classificada como REM (24,07\%), levando a uma imprevisão da classe.

Tabela 3 - Matriz de Confusão da classificação e Índice de Concordância Kappa da classificação de cobertura florestal

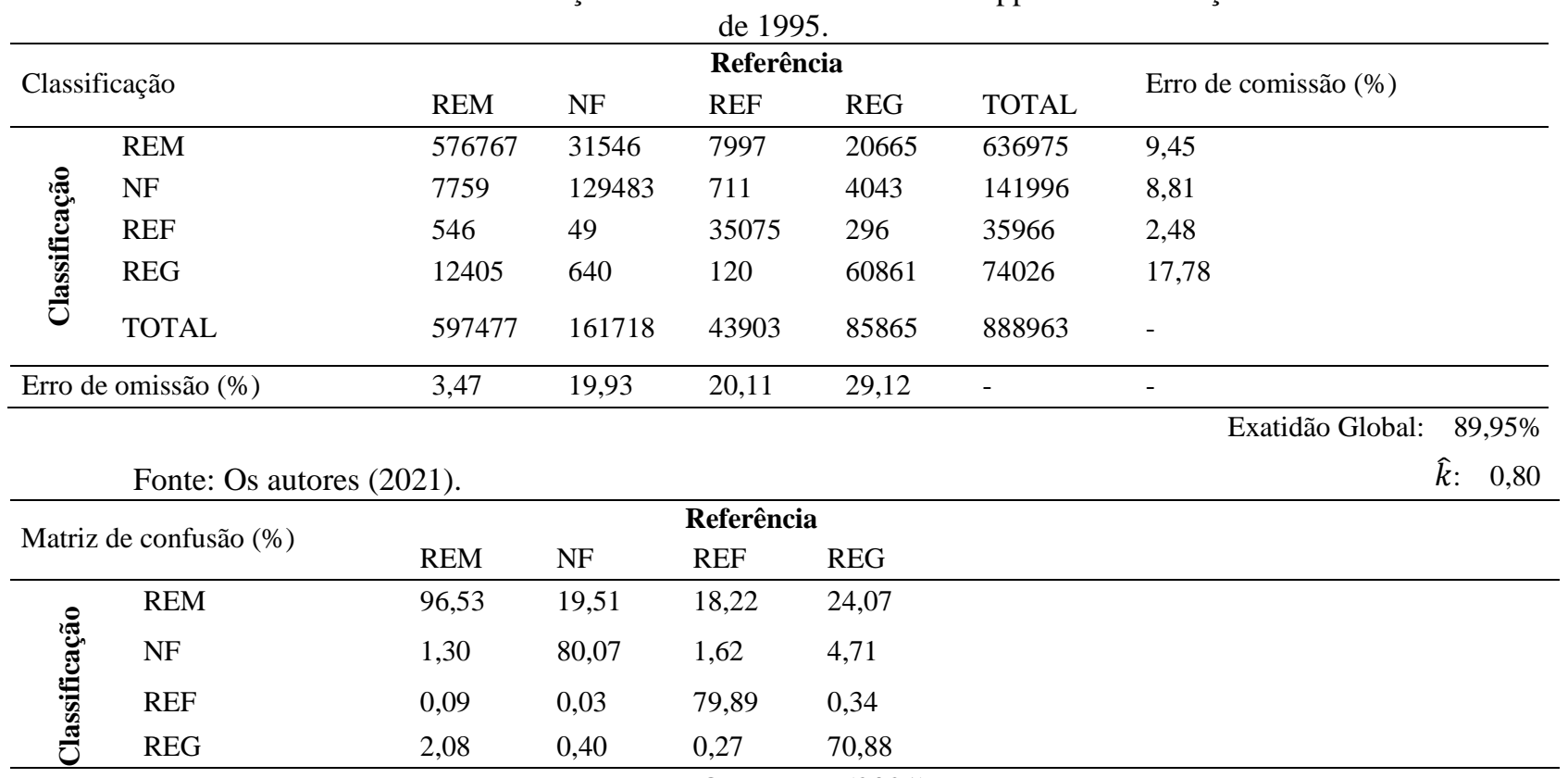

Fonte: Os autores (2021).

No entanto, o menor erro de comissão ocorreu na classe REF (2,48\%), e menor erro de omissão ocorreu na classe REM, com apenas $3,47 \%$. Isso sugere que praticamente todos os pixels foram classificados corretamente. A Tabela 4 mostra a matriz de confusão referente ao mapa de 2006, apresentando um coeficiente Kappa estimado de 0,75. A Exatidão Global do mapa foi de $86,78 \%$. A classe REG apresentou a maior porcentagem do erro de comissão no mapa de 2006 (23,29\%) e o maior erro de omissão $(27,02 \%)$, em que 
grande parte dos pixels foi classificada como REM (24,16\%), retratando a dificuldade de identificar e classificar a vegetação regenerada na imagem. A classe que apresentou os menores erros de comissão e omissão foi REM, com 9,43\% e 9,86\%, respectivamente. Tal classe apresentou baixos valores de erros de omissão e comissão, o que significa que quase todos os pixels verdadeiramente pertencentes a REM foi rotulada corretamente.

Tabela 4 - Matriz de Confusão da classificação e Índice de Concordância Kappa da classificação de cobertura florestal de 2006.

\begin{tabular}{|c|c|c|c|c|c|c|c|c|}
\hline \multirow{2}{*}{\multicolumn{2}{|c|}{ Classificação }} & \multicolumn{5}{|c|}{ Referência } & \multirow{2}{*}{\multicolumn{2}{|c|}{ Erro de comissão (\%) }} \\
\hline & & \multirow{2}{*}{$\begin{array}{l}\text { REM } \\
517500\end{array}$} & \multirow{2}{*}{$\begin{array}{l}\text { NF } \\
18921\end{array}$} & \multirow{2}{*}{$\begin{array}{l}\text { REF } \\
8739\end{array}$} & \multirow{2}{*}{$\frac{\text { REG }}{26209}$} & \multirow{2}{*}{$\begin{array}{l}\text { TOTAL } \\
571369\end{array}$} & & \\
\hline & REM & & & & & & 9,43 & \\
\hline ש్ల్ల్ & $\mathrm{NF}$ & 25065 & 117853 & 537 & 2452 & 145907 & 19,23 & \\
\hline se & REF & 9944 & 508 & 54162 & 653 & 65267 & 17,01 & \\
\hline है & REG & 21570 & 1642 & 833 & 79181 & 103226 & 23,29 & \\
\hline & TOTAL & 574079 & 138924 & 64271 & 108495 & 885769 & - & \\
\hline \multicolumn{2}{|c|}{ Erro de omissão (\%) } & 9,86 & 15,17 & 15,73 & 27,02 & - & - & \\
\hline & & & & & & & Exatidão Global: & $86,78 \%$ \\
\hline & & & & & & & & $\hat{k}: \quad 0,75$ \\
\hline \multirow{2}{*}{\multicolumn{2}{|c|}{ Matriz de confusão $(\%)$}} & \multicolumn{5}{|c|}{ Referência } & & \\
\hline & & REM & NF & REF & REG & & & \\
\hline \multirow{4}{*}{ 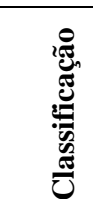 } & REM & 90,14 & 13,62 & 13,60 & 24,16 & & & \\
\hline & NF & 4,37 & 84,83 & 0,84 & 2,26 & & & \\
\hline & REF & 1,73 & 0,37 & 84,27 & 0,60 & & & \\
\hline & REG & 3,76 & 1,18 & 1,30 & 72,98 & & & \\
\hline
\end{tabular}

Fonte: Os autores (2021).

A Tabela 5 mostra a matriz de confusão referente ao mapa de 2017, apresentando um coeficiente Kappa estimado de 0,79. A Exatidão Global do mapa foi de 87,41\%.

O maior erro de omissão foi na classe REG $(31,79 \%)$ e maior erro de comissão foi na classe NF $(16,37 \%)$, superestimando as áreas não-florestais. A classe REM apresentou o menor erro de omissão com apenas $3,10 \%$, assim como nos anos anteriores.

Tabela 5 - Matriz de Confusão da classificação e Índice de Concordância Kappa da classificação de cobertura florestal

\begin{tabular}{|c|c|c|c|c|c|c|c|}
\hline \multirow{2}{*}{\multicolumn{2}{|c|}{ Classificação }} & \multicolumn{5}{|c|}{ Referência } & \multirow{2}{*}{ Erro de comissão (\%) } \\
\hline & & REM & $\mathrm{NF}$ & REF & REG & TOTAL & \\
\hline \multirow{5}{*}{ 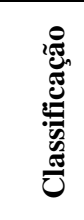 } & REM & 529077 & 27336 & 21880 & 35864 & 614157 & 13,85 \\
\hline & NF & 10262 & 82152 & 1379 & 4442 & 98235 & 16,37 \\
\hline & REF & 3133 & 132 & 67151 & 2075 & 72491 & 7,37 \\
\hline & REG & 3529 & 441 & 328 & 90947 & 95245 & 4,51 \\
\hline & TOTAL & 546001 & 110061 & 90738 & 133328 & 880128 & - \\
\hline \multicolumn{2}{|c|}{ Erro de omissão (\%) } & 3,10 & 25,36 & 25,99 & 31,79 & - & - \\
\hline & & & & & & & $\begin{array}{r}\text { Exatidão Global: } 87,41 \% \\
\hat{k}: \quad 0,76\end{array}$ \\
\hline \multirow{2}{*}{\multicolumn{2}{|c|}{ Matriz de confusão $(\%)$}} & \multicolumn{5}{|c|}{ Referência } & \\
\hline & & REM & $\mathrm{NF}$ & REF & REG & & \\
\hline \multirow{4}{*}{ 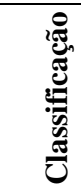 } & REM & 96,90 & 24,84 & 24,11 & 26,90 & & \\
\hline & NF & 1,88 & 74,64 & 1,52 & 3,33 & & \\
\hline & REF & 0,57 & 0,12 & 74,01 & 1,56 & & \\
\hline & REG & 0,65 & 0,40 & 0,36 & 68,21 & & \\
\hline
\end{tabular}

Fonte: Os autores (2021).

A Tabela 6 exibe as áreas regeneradas e desmatadas calculadas entre períodos 1985-1995, 1995-2006 e 2006-2017 dentro das UCs no Vale do Ribeira (VR). Nota-se que durante todo o período analisado entre 1985 e 2017, houve perda florestal de remanescentes de Mata Atlântica em torno de 22\% dentro das UC pertencentes ao Vale do Ribeira, sendo que o período de maior decréscimo florestal nessas áreas foi nas últimas 
décadas (2006-2017). Neste caso, estima-se que quase 1/5 do desmatamento estimado para esse período de todo o Vale do Ribeira ocorreu dentro de uma área protegida.

Tabela 6 - Área das dinâmicas de regeneração e desmatamento em 1985-1995, 1995-2006, 2006-2017 e 1985-2017 dentro das Unidades de Conservação $\left(\mathrm{km}^{2}\right)$ e sua representação em relação a todo Vale do Ribeira (\%).

\begin{tabular}{lcc|c|ccc|c|ccc|cc}
\hline & \multicolumn{1}{c}{ Veríodo } \\
\cline { 2 - 13 } Dinâmica florestal & VR & UCs & $\%$ & VR & UCs & $\%$ & VR & UCs & $\%$ & VR & UCs & $\%$ \\
\hline Regeneração $\left(\mathrm{km}^{2}\right)$ & 2054,63 & 506,08 & 24,6 & 1720,12 & 409,33 & 23,8 & 2135,29 & 586,05 & 27,4 & 4299,28 & 1289,39 & 30,0 \\
Desmatamento $\left(\mathrm{km}^{2}\right)$ & 1323,36 & 240,71 & 18,2 & 1285,10 & 199,43 & 15,5 & 976,41 & 216,46 & 22,2 & 1214,70 & 264,32 & 21,8 \\
\hline
\end{tabular}

Para culminar, a maior perda líquida florestal total de remanescentes na área de estudo foi observada entre 1985 e 1995, aproximadamente 1,3 mil km². Desse valor percentual, cerca de $18 \%$ está localizado dentro das UCs. Neste caso, esse fato contraria o propósito da criação de áreas protegidas, visto que cerca de $40 \%$ das UCs no Vale do Ribeira foram criadas antes ou durante esse período compreendido entre 1985 a 1995.

Apesar das ocorrências de perda florestal observada entre o período 1985 a 2017 em UC, cerca de 30\% dos ganhos florestais por regeneração encontra-se nas mesmas áreas, ou seja, pode-se dizer que este foi capaz de suprir o desmatamento dentro das Unidades de Conservação pertencentes ao Vale do Ribeira. Por outro lado, essa porcentagem de áreas regeneradas é considerada ínfima comparada ao total regenerado em todo Vale do Ribeira, cerca de 4,3 mil km², o que sugere que a regeneração aconteceu de forma heterogênea e esparsa em toda a região.

O período de maior contribuição de regeneração total no Vale do Ribeira foi entre 2006 e 2017, com cerca de 2,1 mil km², sendo que em torno de $27 \%$ desse ganho está localizado dentro das Unidades de Conservação. A Figura 3 retrata as áreas de desmatamento e regeneração por cada Unidade de Conservação e na Figura 4 é apresentada a espacialização das dinâmicas florestais ocorrentes nas UC entre 1985 e 2017.

Nota-se que, com exceção de todas as APA (1 ao 7), os PE Caverna do Diabo (11) e Rio do Turvo (14) e os RDS Barreiro Anhemas (19), dos Pinheiros (20) e Quilombos de Barra do Turvo (23), as Unidades de Conservação apresentaram aproximadamente desmatamento zero. Entretanto, são essas mesmas regiões que, somados, registraram $82 \%$ dos ganhos florestais devido à regeneração, com relação à regeneração calculada em todas as Unidades de Conservação dentro do Vale do Ribeira. Concidentemente, destas UCs citadas, apenas as unidades 11 e 14 são classificados como Proteção Integral.

Além disso, percebe-se que nas Unidades de Conservação de Uso Sustentável, o percentual de território desmatado chegava a 82,7\%, enquanto nas Unidades de Conservação de Proteção Integral, essa proporção foi menor, com cerca de $17 \%$. Por outro lado, a proporção de regeneração nas UCs de PI foi maior do que as de US. Nas unidades de PI, o ganho líquido florestal foi de $381,06 \mathrm{~km}^{2}$, com fator de 8 vezes a área desmatada, enquanto nas unidades de US, o ganho líquido florestal foi de $644,02 \mathrm{~km}^{2}$, com fator de 3 . A Tabela 7 mostra a relação entre as dinâmicas florestais por tipo de UC e sua representação em relação ao valor total.

Tabela 7 - Área das dinâmicas de regeneração e desmatamento em unidades de Proteção Integral e Uso Sustentável entre 1985 e 2017.

\begin{tabular}{lccccc}
\hline \multicolumn{4}{c}{ Análise das dinâmicas florestais por tipo de Unidade } & \\
\hline Dinâmica florestal & \multicolumn{2}{c}{ Proteção Integral } & & Uso Sustentável & \multicolumn{2}{c}{ Total } \\
\hline Desmatamento $\left(\mathrm{km}^{2}\right)$ & 45,80 & $17,3 \%$ & 218,52 & $82,7 \%$ & 264,32 \\
Regeneração $\left(\mathrm{km}^{2}\right)$ & 426,86 & $33,1 \%$ & 862,54 & $66,9 \%$ & 1289,39 \\
\hline
\end{tabular}

Fonte: Os autores (2021).

Ao analisar a Figura 4, nota-se que os maiores remanescentes florestais em áreas contínuas foram observados (classe sem mudança) principalmente nas porções centrais situadas entre o Parque Estadual Intervales, Parque Estadual Carlos Botelho e Parque Estadual do Rio Turvo no período entre 1985 e 2017, formando um cinturão de proteção ambiental no meio do Vale do Ribeira. Vale salientar que tais unidades são da categoria Proteção Integral. 
Figura 3 - Desmatamento e regeneração nas UC localizadas na região do Vale do Ribeira entre 1985 e 2017. Legenda: 1- APA Cajati; 2- APA de Canananéia-Iguape-Peruíbe; 3 - APA Ilha Comprida; 4- APA Planalto do Turvo; 5- APA Quilombos do Médio Ribeira; 6- APA Rio Pardinho e Rio Vermelho; 7- APA Serra do Mar; 8- EE Chaúas; 9- PE da Ilha do Cardoso; 10- PE Carlos Botelho; 11- PE Caverna do Diabo; 12- PE da Campina do Encantado; 13- PE de Campinhos; 14- PE do Rio do Turvo; 15- PE Intervales; 16- PE Lagamar de Cananéia; 17- PE Turístico do Alto do Ribeira; 18- PN Municipal Morro do Ouro; 19- RDS Barreiro Anhemas; 20- RDS dos Pinheirinhos; 21- RDS Itapanhapima; 22- RDS Lavras; 23- RDS Quilombos de Barra do Turvo; 24- RESEX Ilha do Tumba; 25- RESEX Mandira; 26- RESEX Taquari; 27- RPPN Papagaio de Peito Roxo.

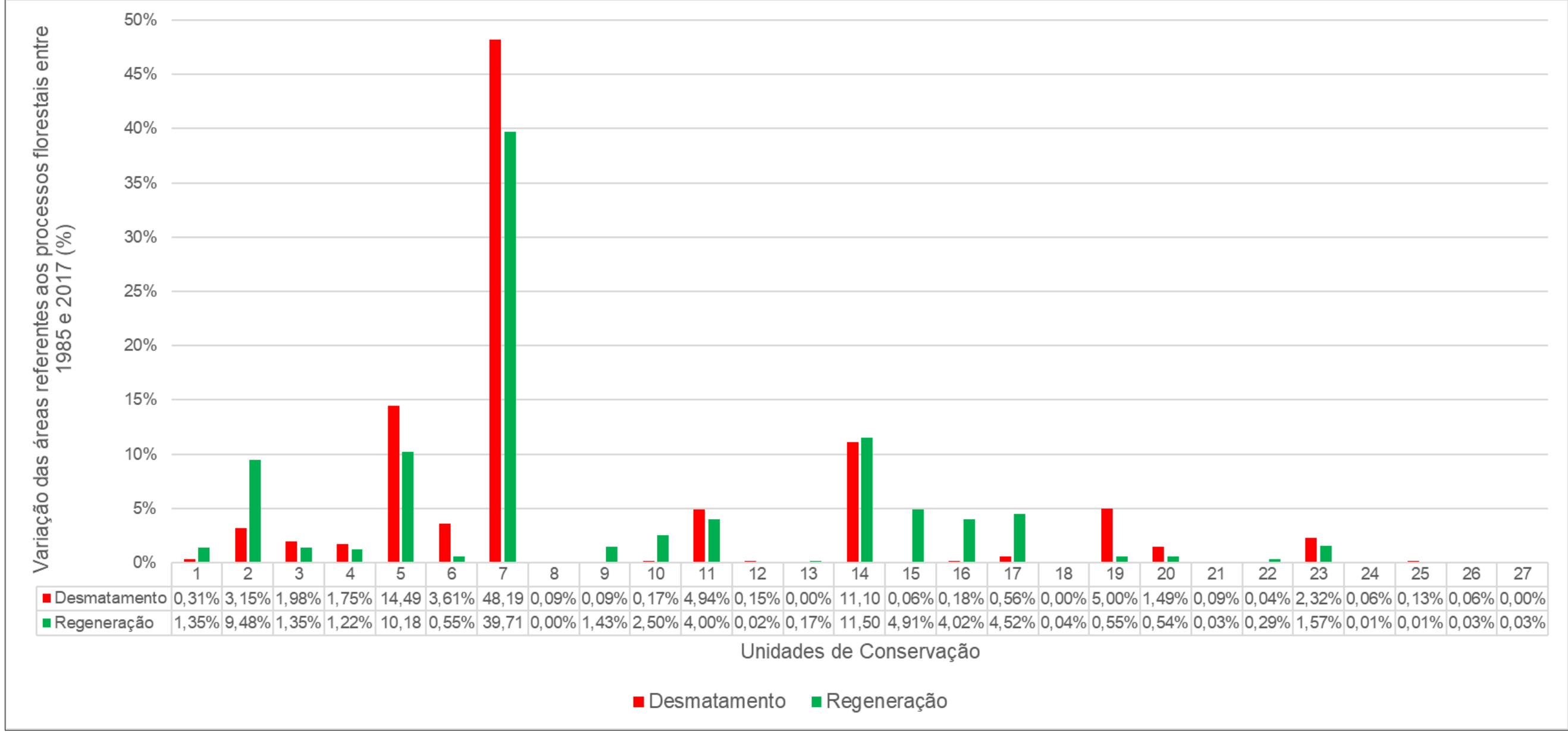

Fonte: Os autores (2021). 
Figura 4 - Espacialização da dinâmica florestal de desmatamento e regeneração nas UC localizadas na região do Vale do Ribeira entre 1985 e 2017. Legenda: 1- APA Cajati; 2- APA de Canananéia-Iguape-Peruíbe; 3- APA Ilha Comprida; 4- APA Planalto do Turvo; 5- APA Quilombos do Médio Ribeira; 6- APA Rio Pardinho e Rio Vermelho; 7- APA Serra do Mar; 8- EE Chaúas; 9- PE da Ilha do Cardoso; 10- PE Carlos Botelho; 11- PE Caverna do Diabo; 12- PE da Campina do Encantado; 13- PE de Campinhos; 14- PE do Rio do Turvo; 15- PE Intervales; 16- PE Lagamar de Cananéia; 17- PE Turístico do Alto do Ribeira; 18- PN Municipal Morro do Ouro; 19- RDS Barreiro Anhemas; 20- RDS dos Pinheirinhos; 21- RDS Itapanhapima; 22RDS Lavras; 23- RDS Quilombos de Barra do Turvo; 24- RESEX Ilha do Tumba; 25- RESEX Mandira; 26- RESEX Taquari; 27- RPPN Papagaio de Peito Roxo.

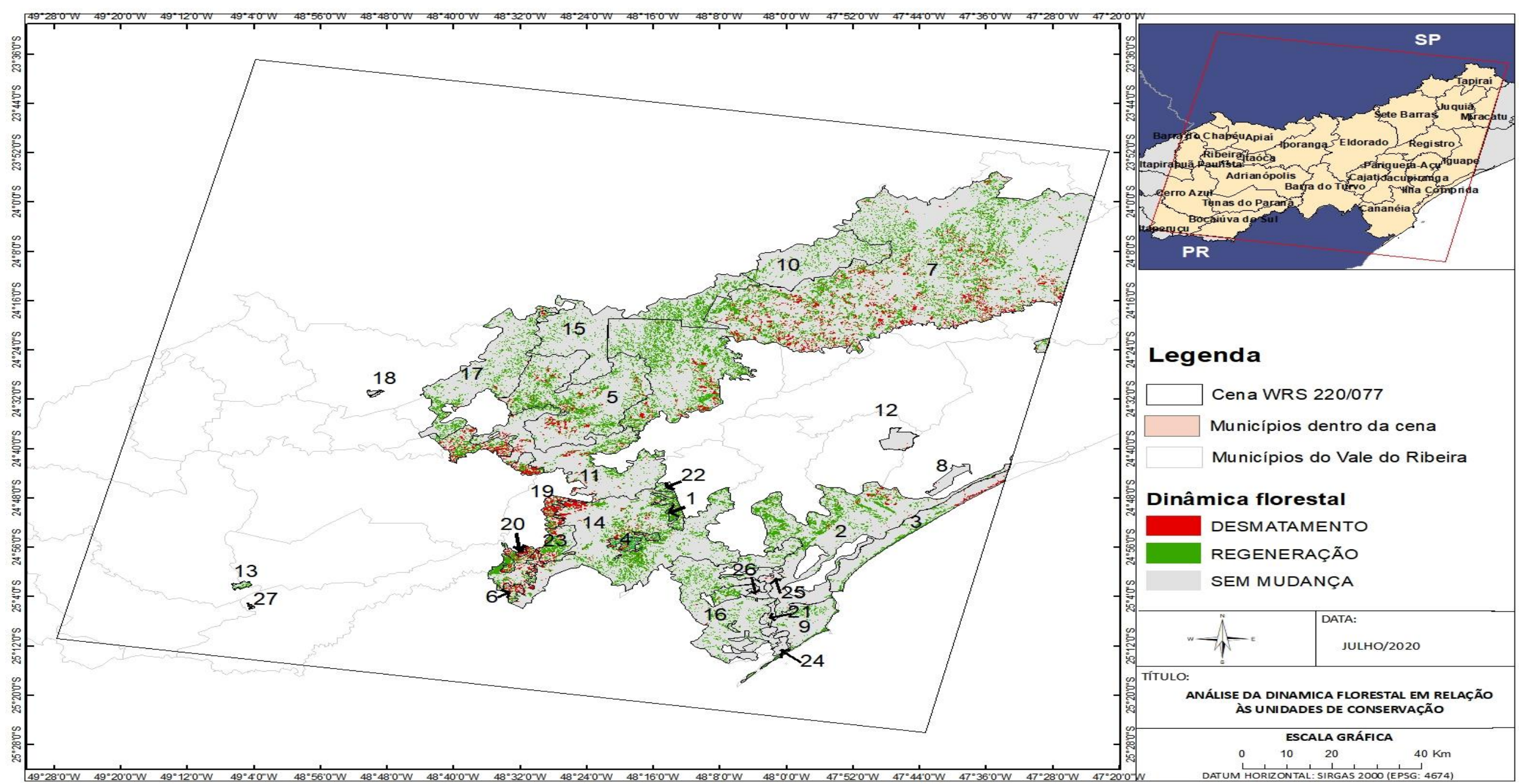

Fonte: Os autores (2021). 


\section{DISCUSSÃO}

Notou-se um padrão do algoritmo CML relacionando as classes com maiores concordância em todos os anos analisados, ou seja, classes que apresentaram pixels corretamente classificados. Neste caso, a ordem decrescente em relação à conformidade das classes observada foi: REM, NF, REF e REG, visto que a classe regeneração apresentou maior confusão com as outras classes.

Existem diferentes trabalhos na literatura dedicados à comparação de algoritmos de classificação, com especial atenção ao uso de algoritmos supervisionados. Podem ser citados Moreira et al. (2016), Reis (2013) e Nery et al. (2013). Em todos esses trabalhos, diferentes classificadores supervisionados foram testados utilizando o mesmo conjunto de classes específicas, com um único conjunto de amostras de treinamento e seus resultados avaliados por meio de índices de exatidão derivados de matrizes de confusão, as quais são geradas pela tabulação das classificações com amostras de referência.

Assim como o estudo realizado por Reis et al. (2017b), o qual os autores classificaram suas imagens em nível mais detalhado definido por dez classes específicas, adquiriu-se amostragens para cada classe observada nas imagens analisadas no presente trabalho. No entanto, não teve um número específico de classes definidas para todas as imagens, mas sim, foram obtidas amostras as mais detalhadas possíveis capaz de distinguir os diferentes alvos identificados em cada imagem, uma independente da outra.

Para se ter uma ideia do desempenho do CML, a Tabela 8 apresenta os valores do Índice Kappa calculado por Reis et al. (2017b) comparando diferentes algoritmos analisados. Observa-se que todos os classificadores obtiveram valores de Kappa esperado estatisticamente diferentes entre si, a $1 \%$ de significância. Nota-se ainda que os resultados mais acurados foram obtidos pelo classificador MAXVER, pois trata-se de um algoritmo mais simples por não precisar de ajustes de parâmetros.

Tabela 8 - Valores de Kappa e de incerteza média dos diferentes algoritmos analisados.

\begin{tabular}{rl}
\hline Algoritmo & Kappa \\
\hline MAXVER & $0,700 \pm 0,013$ \\
K-NN & $0,692 \pm 0,014$ \\
$J 48$ & $0,674 \pm 0,017$ \\
SVM & $0,698 \pm 0,014$ \\
\hline
\end{tabular}

Fonte: Reis et al. (2017b).

Um comparativo entre os dados obtidos por Duarte (2019) e Silva (2018), os quais o processo de classificação foi utilizando o método tradicional MAXVER de classificação, os índices estimados foram menores entre os anos analisados, diferentemente do apresentado nesse presente trabalho. Como esperado, os resultados obtidos utilizando o CML mostraram-se mais satisfatórios, com valores dos índices de mesma ordem e similares entre os anos, e consequentemente, menores erros associados nas matrizes de confusão, indicando uma maior consistência de informação.

Percebe-se que em algumas UCs tiveram eventos recorrentes de desmatamento. Tais acontecimentos podem estar relacionados aos eventos naturais de degradação ambiental e a eventos extremos, como erosão e deslizamento de árvores, abertura de clareira, ou até mesmo erros de processamento e classificação da imagem, em detrimento das limitações do classificador e do analista.

Em relação ao Parque Estadual Rio Turvo, este apresenta um histórico de muitas agressões ao patrimônio natural e social, desde a retirada ilegal de madeira para comercialização clandestina, a formação de pastagens por fazendeiros com desmatamentos e queimadas, e madeireiros (BIM; FURLAN, 2013). Além disso, a rodovia Régis Bittencourt (BR-116) transcende o Parque, favorecendo o processo de desmatamento em favor à gestão e à fiscalização da estrada.

Esse padrão de desmatamento e degradação da cobertura florestal próximo às rodovias é recorrente também em outros biomas. Na história recente de ocupação da Amazônia, por exemplo, as estradas sempre tiveram papel estratégico para impulsionar a perda da cobertura florestal, tendo as áreas desflorestadas concentradas nos primeiros $2.500 \mathrm{~m}$ de distância das estradas no sudoeste paraense (SOUZA et al., 2017). 
Além disso, a criação e implantação de um mosaico de áreas protegidas de diferentes categorias de manejo (proteção integral, uso sustentável e terras indígenas) ao longo das rodovias na Amazônia é uma excelente estratégia para conter o desflorestamento (BORGES, FERREIRA, 2011).

Com relação à APA de Cananéia-Iguape-Peruíbe, por ser uma região litorânea, o turismo e a especulação imobiliária colaboraram para os processos de povoamento na região, por meio da venda de lotes e terrenos (DIAS, 2012). Tais fatos combinados com a falta de fiscalização, resultou no desmatamento na região. Entretanto, essa região foi a segunda maior em relação à contribuição para a regeneração dentro de uma Unidade de Conservação.

Por outro lado, a APA de Cananéia-Iguape-Peruíbe juntamente ao PE da Ilha do Cardoso, PE Carlos Botelho, PE Intervales, PE Lagamar de Cananéia e PE Turístico do Alto do Ribeira foram as UCs em que a regeneração foram mais significativas e superiores às ocorrências de desmatamento na região. Com exceção da primeira unidade, as demais se enquadram em UC do tipo Proteção Integral. Tendo em vista que o uso dos recursos naturais nessa categoria é controlado e de forma indireta, isso faz com que seja proporcionado uma maior proteção dos ecossistemas, além de facilitar a conectividade entre os remanescentes florestais para a formação de fragmentos maiores, a partir da recomposição da vegetação (RUSCA et al., 2017), em conformidade com o que foi observado na área de estudo.

Acerca da localização espacial de tais UCs, constatou-se que estas se encontram internalizadas na parte central do Vale do Ribeira, o que favorece a formação de um grande sistema de proteção ambiental (ALVES, 2004; MUNARI, 2009; RIBEIRO FILHO, 2015; SOUZA, 2017), além de permitir a ocorrência da sucessão natural florestal local em detrimento da disponibilidade de bancos de sementes. Desse modo, a concepção da formação de um grande cinturão ambiental corrobora com as ideias de Morais et al. (2017), ao afirmar que, para que os objetivos das UCs sejam alcançados em longo prazo, as mesmas não devem apenas atuar como unidades isoladas, mas também manter redes de fragmentos interligados, levando em consideração as pressões e os recursos presentes em seu entorno.

Pode-se dizer, então, que a iniciativa para criação de mosaicos proporciona vários benefícios florestais, perspectiva que ajuda consolidar ações efetivas para a conservação da biodiversidade e dos serviços ecossistêmicos (BRAGA, 2016; CELENTANO et al., 2018). Posto a importância das UCs para a minimização das atividades antrópicas e recuperação ambiental dentro dos limites das áreas protegidas, tal contexto foi abordado por Pinheiro e Rezende (2012) ao constatarem que os municípios que mais desmatavam na Amazônia Legal reduziram os seus índices de desmatamento após a criação de UCs, demonstrando a importância dessa política ambiental no controle da retirada de vegetação, e por tanto, tendo essa temática ambiental enaltecida neste presente trabalho.

\section{CONCLUSÃO}

A metodologia aplicada mostrou-se eficaz e bastante confiável. Os resultados apresentados dimensionam a enorme importância das Unidades de Conservação para aumentar a proteção dos remanescentes do bioma Mata Atlântica, tendo em vista as áreas desmatadas estimadas praticamente zero na maioria das UCs. Este estudo indica que o desmatamento sofreu um decréscimo dentro dos limites das Unidades de Conservação ao longo de mais de trinta anos analisados à medida que o planejamento e medida públicas foram se tornando mais rígidas.

Este fato demonstra a importância da interligação do sistema de proteção ambiental, aliada às operações de fiscalização em áreas prioritárias para a prevenção e controle do desmatamento conduzido pela Ibama e Instituições Parceiras. Assim, uma gestão mais atenta às informações disponíveis para o planejamento, administração e fiscalização das Unidades de Conservação deve ser realizada para continuar a inibição de reincidência de desmatamento e promover a conexão entre fragmentos remanescentes e regenerados para as UCs no Vale do Ribeira.

\section{Agradecimentos}

O presente trabalho foi realizado com apoio da Coordenação de Aperfeiçoamento de Pessoal de Nível 
Superior - Brasil (CAPES) - Código de Financiamento 001.

\section{Contribuição dos Autores}

Os autores contribuíram igualmente em todas as etapas de elaboração do artigo, da sua concepção e investigação à redação do texto final.

\section{Conflitos de Interesse}

Os autores declaram que não há conflitos de interesse.

\section{Referências}

ALVES, H. P. F. Análise dos fatores associados às mudanças na cobertura da terra no Vale do Ribeira através da integração de dados censitários e de sensoriamento remoto. 2004. 337 p. Tese (Doutorado em Ciências Sociais) - IFCH, Campinas, 2004.

ARONSON, J.; DURIGAN, G.; BRANCALION, P. H. S. Conceitos e definições correlatos à ciência e à prática da restauração ecológica. IF Sér. Reg., n. 44, p. 1-38, 2011.

BIM, O. J. B.; FURLAN, S. A. Mosaico do Jacupiranga -Vale da Ribeira/SP: conservação, conflitos e soluções socioambientais. AGRÁRIA, São Paulo, n. 18, p. 4-36, 2013.

BORGES, C. A. R. F.; FERREIRA, L. V. O processo de desflorestamento nas rodovias do estado do Pará: um estudo de caso da rodovia Transamazônica (BR-230). In: Simpósio Brasileiro de Sensoriamento Remoto, 15, 2011, Curitiba-PR, Brasil. Anais..., São José dos Campos, INPE, 2011, p. 2796-2803.

BRAGA, A. R. O. Estrutura da paisagem e a conectividade entre os fragmentos florestais do entorno da cidade universitária do estado do Amazonas. 2016. 69 p. Dissertação (Mestrado em Gestão de Áreas Protegidas no Amazonas) - INPA, Manaus-AM, 2016.

BRASIL. Ministério do Meio Ambiente. SNUC - Sistema Nacional de Unidades de Conservação da Natureza: Lei $n^{\circ}$ 9.985, de 18 de julho de 2000; Decreto $n^{\circ} 4.340$, de 22 de agosto de 2002; Decreto $n^{\circ} 5.746$, de 5 de abril de 2006. Plano Estratégico Nacional de Áreas Protegidas: Decreto n ${ }^{\circ} 5.758$, de 13 de abril de 2006. Brasília: MMA, 2011. 76 p.

CASTILLO, E.M.D.; MARTIN, A.G.; ALADRÉN, L.A.L. \& LUIS, M. Evaluation of Forest Cover Change Using Remote Sensing Techniques and Landscape Metrics in Moncayo Natural Park (Spain). Revista Applied Geography, n. 62, p. 247-255, 2015.

CELENTANO, D., MIRANDA, M. V. C.; MEDONÇA, E. N.; ROUSSEAU, G. X.; MUNIZ, F. H.; LOCH, V. C.; VARGA, I. V. D.; FREITAS, L.; ARAÚJO, P.; NARVAES, I. S.; ADAMI, M.; GOMES, A. R.; RODRIGUES, J. C.; KAHWAGE, C.; PINHEIRO, M.; MARTINS, M. B. Desmatamento, degradação e violência no Mosaico Gurupi - A região mais ameaçada da Amazônia. Estudos Avançados, n. 32, v. 92, p. 315-339, 2018.

COMITÊ DA BACIA HIDROGRÁFICA DO RIO RIBEIRA DE IGUAPE E LITORAL SUL (CBH-RB). PLANO DE BACIAS DA UGRHI 11. Relatório I. São Paulo, 2016. Disponível em:< http://comiterb.com.br/wp-content/uploads/2018/07/Plano-de-Bacia-CBH-RB-Relatorio-I.pdf >.Acesso em: 03 fev. 2020.

PLANO DE BACIAS DA UGRHI 11. Relatório II. São Paulo, 2018. Disponível em:<http://comiterb.com.br/wp-content/uploads/2018/07/Plano-de-Bacia-CBH-RB-Relat\%C3\%B3rioII.pdf $>$.Acesso em: 03 fev. 2020.

COSTA, R. L.; PREVEDEllO, J. A.; SOUZA, B. G.; CABRAL, D. C. Forest transitions in tropical landscapes: A test in the Atlantic Forest biodiversity hotspot. Applied Geography, v. 82, p. 93-100, 2017.

DEVRIES, B. et al. Robust monitoring of small-scale forest disturbances in a tropical montane forest using Landsat time series. Remote Sensing of Environment, v.161, p.107-121, 2015. 
DIAS, R. L. Zoneamento geoambiental da região do litoral sul do Estado de São Paulo como subsídio ao uso e ocupação das terras: um estudo de caso dos municípios de Iguape, Ilha Comprida e Cananeia. 2012. 204 f. Dissertação (Mestrado em Geografia) - Universidade Estadual de Campinas, Campinas, 2012.

DUARTE, J. F. S. Mudanças da cobertura da terra e transição florestal no Vale do Paraíba. 2019. 144 p. Dissertação (Mestrado em Sensoriamento Remoto) - INPE, São José dos Campos-SP, 2019.

EMPRESA BRASILEIRA DE PESQUISA AGROPECUÁRIA (EMBRAPA). Cerrado: Restauração de Matas de Galeria e Ciliares. Embrapa: Brasília, 2012. Disponível em:<http://www.cpac.embrapa.br/publico/usuarios/uploads/Downloads/Cartilha\%20embrapa\%20mata\% 20riparia(1).pdf>.Acesso em: 30 dez. 2019.

FAVRETO, R. Aspectos etnoecológicos e ecofisiológicos de Euterpe edulis Mart. (Arecaceae). 2010, 144 f. Tese (Doutorado em Ciências Biológicas - Botânica) - Universidade Federal do Rio Grande do Sul, Porto Alegre-RS, 2010.

FERREIRA, M. P.; ALVES, D. S.; SHIMABUKURO, Y. E. Forest dynamics and land-use transitions in the Brazilian Atlantic Forest: the case of sugarcane expansion. Regional Environmental Change, v. 15, n. 2, p. 365-377, 2015.

FUNDAÇÃO SOS MATA ATLÂNTICA/INPE. Mata Atlântica. 2019. Disponível em:< https://www.sosma.org.br/conheca/mata-atlantica/>.Acesso em: 21 fev. 2019.

Unidades de Conservação Municipais da Mata Atlântica. São Paulo: INPE, 2017. Disponível em:< https://www.sosma.org.br/wp-content/uploads/2017/07/SOSMA-UCs_WEB.pdf/>.Acesso em: 21 fev. 2019.

INSTITUTO AGRONÔMICO DE CAMPINAS (IAC). Macrozoneamento das Terras da Região do Rio Ribeira de Iguape. Campinas, 1990.

MACIEL, A. L. Investigação da hipótese de transição florestal no Vale do Ribeira (SP/PR) usando imagens de sensoriamento remoto e dados agrícolas/demográficos. 2020. 153 p. Dissertação (Mestrado em Sensoriamento Remoto) - INPE, São José dos Campos-SP, 2020.

MINISTÉRIO DO MEIO AMBIENTE (MMA). Dados georreferenciados. 2020. Disponível em: <https://www.mma.gov.br/areas-protegidas/cadastro-nacional-de-ucs/dadosgeorreferenciados.html>. Acesso em: 01 fev. 2020.

. Mata Atlântica: patrimônio nacional dos brasileiros. Secretaria de Biodiversidade e Florestas. Núcleo Mata Atlântica e Pampa; organizadores Maura Campanili [e] Wigold Bertoldo Schaffer. Brasília: MMA, 2010.

MORAES, M. C. P.; MELLO, K.; TOPPA, R. H. Protected areas and agricultural expansion: Biodiversity conservation versus economic growth in the Southeast of Brazil. Journal of Environmental Management, v. 188, p 73-84, 2017.

MOREIRA, E. F.; SANTOS, R. L. S.; FRANÇA ROCHA, W. J. S.; BOSCOLO, D.; PIGOZZO.C. M. Comparação e desempenho dos algoritmos paramétricos na classificação supervisionada de áreas naturalmente heterogêneas e dinâmicas. Revista Brasileira de Cartografia, v.3, n. 68, p.581-594, 2016.

MUNARI, L. C. Memória social e ecologia: a agricultura de coivara das populações quilombolas do Vale do Ribeira e sua relação com a formação da Mata Atlântica local. 2009. 218 p. Dissertação (Mestrado em Ciências, na área de Ecologia) - Universidade de São Paulo, São Paulo-SP, 2009.

NERY, C.V.M.; FERNANDES, F.H.S.; MOREIRA, A.A.; BRAGA, F.L.B. Avaliação das técnicas de classificação MAXVER, MAXVER - ICM e Distância Mínima Euclidiana de acordo com Índice Kappa. Revista Brasileira de Geografia Física, v.6, n. 2, p. 11-219, 2013.

PALUDO, G.F. et al. Estimativas de Produção de Frutos de Palmiteiro (Euterpe edulis Mart.) a partir da Densidade de Indivíduos. Biodiversidade Brasileira, v. 2, n. 2, p. 92-102, 2012.

PINHEIRO, E. S; REZENDE, MGG. Análise do desflorestamento no sul do Amazonas. Revista Acta Geográfica, v. 6, n. 13, 2012.

PONZONI, F. J. Comportamento espectral da vegetação. 2001. In: P. R. MENESES; J. S. MADEIRA NETTO 
(Org.), Sensoriamento remoto - refletância de alvos naturais. Brasília: Ed. UnB / Embrapa Cerrados. $262 \mathrm{p}$.

PONZONI, F. J.; SHIMABUKURO, Y. E. 2010. Sensoriamento remoto no estudo da vegetação. São José dos Campos: Ed. Parênteses, 136 p.

REIS, M. S. Comparação entre os classificadores máxima verossimilhança, SVM e rede neural MLP para uso e cobertura da terra em parcela da FLONA Tapajós e Arredores. In: SIMPÓSIO BRASILEIRO DE SENSORIAMENTO REMOTO, 16. (SBSR), 2013, Foz do Iguaçu. Anais... São José dos Campos: INPE, 2013. p. 2377-2383.

REIS, M. S.; DUTRA, L. V.; ESCADA, M. I. S. Simultaneous multi-source and multi-temporal land cover classification using a Compound Maximum Likelihood classifier. In: GEOINFO, 18., 2017a, Salvador, BA, Brazil. Proceedings... São José dos Campos: INPE, 2017a. p. 74-85.

REIS, M. S.; DUTRA, L. V.; SANT’ANNA, S. J. S.; ESCADA, M. I. S. Análise das incertezas envolvidas em classificação multi-legendas da cobertura da terra com suporte de simulação Monte Carlo. Revista Brasileira de Cartografia, v. 9, n. 69, 2017b.

RESENDE, R. U. Plano territorial de desenvolvimento rural sustentável Território Vale do Ribeira (SP). Brasília: MDA, 2011.

REZENDE, C. L.; SCARANO, F. R.; ASSAD, E. D.; JOLY, C. A.; METZGER, J. P.; STRASSBURG, B. B. N.; TABARELlI, M.; FONSECA, G. A.; MITTERMEIER, R. A. From hotspot to hopespot: An opportunity for the Brazilian Atlantic Forest. Perspectives in Ecology and Conservation, v. 16, n. 4, p. 208-214, 2018.

RIBEIRO FILHO, A. A. Impactos do sistema agrícola itinerante sobre os solos de remanescente de Mata Atlântica com uso e ocupação por comunidades quilombolas do Vale do Ribeira (São Paulo, Brasil). 2015. 387 p. Tese (Doutorado em Ciências, na área de Ecologia de Ecossistemas Terrestres e Aquáticos) - Instituto de Biociências, Universidade de São Paulo, São Paulo, 2015.

RIBEIRO, M. C.; METZGER, J. P.; MARTENSEN, A. C.; PONZONI, F. J.; HIROTA, M. M. The Brazilian Atlantic Forest: How much is left, and how is the remaining forest distributed? Implications for conservation. Biological conservation, v. 142, n. 6, p. 1141-1153, 2009.

RUSCA, G. G.; MORAES, M. C. P.; VALENTE, R. A.; PINÃ-RODRIGUES, F. C. M. Análise espacial dos fragmentos florestais no entorno de uma unidade de conservação de proteção integral. RBCIAMB, n. 44, p. 85-94, 2017.

SANTOS, K. M. P.; SILVA, R. J. N.; ALEXANDRE, A. A.; KANIKADAN, A. Y. S.; GARAVELLO, M. E. P. E. Manutenção do sistema agroalimentar em território de conservação ambiental: o caso da APA Planalto do Turvo/Vale do Ribeira/SP. Revista NERA, v.19, n. 33, p. 47-62, 2016.

SILVA, A. L. Transição florestal e dinâmica de uso e cobertura da terra no centro-sul paulista. 2018. 124 p. Dissertação (Mestrado em Sensoriamento Remoto) - Instituto Nacional de Pesquisas Espaciais (INPE), São José dos Campos, 2018.

SILVA, K. R. As técnicas de agricultura tradicional em combinação com propostas e práticas de sistemas agroflorestais: consensos possíveis ao desenvolvimento sustentável da Reserva de Desenvolvimento Sustentável Quilombos de Barra do Turvo, Vale do Ribeira (SP). 2013. $84 \mathrm{f}$. Trabalho de conclusão de curso (Ecologia) - Universidade Estadual Paulista, Instituto de Biociências de Rio Claro, 2013.

SILVA, R. F. B.; BATISTEllA, M.; MORAN, E. F.; LU, D. Land Changes Fostering Atlantic Forest Transition in Brazil: evidence from the Paraíba Valley. The Professional Geographer, v. 69, n. 1, p. 114, 2016.

SISTEMA DE INFORMAÇÕES TERRITORIAIS (SIT). Vale do Ribeira. 2015. Disponível em:<http://sit.mda.gov.br/download/caderno/caderno_territorial_100_Vale\%20do\%20Ribeira\%20\%20SP.pdf >. Acesso em: 21 fev. 2019.

SISTEMA INTEGRADO DE GERENCIAMENTO DE RECURSOS HÍDRICOS DO ESTADO DE SÃO 
PAULO (SIGRH). Comitê da Bacia Hidrográfica do Ribeira de Iguape e Litoral Sul. 2020. Disponível em: <http://www.sigrh.sp.gov.br/cbhrb/apresentacao>. Acesso em: 04 jun. 2020.

SOUZA, A. A. A.; PONTES, A. N.; ADAMI, M.; NARVAES, I. S. A contribuição das estradas e o padrão de desflorestamento e degradação da cobertura florestal no sudoeste paraense. Revista Brasileira de Cartografia, Rio de Janeiro, v. 9, n. 69, p. 1711-1724, Nov/Dez/2017.

SOUZA, P. B. Direitos, comunidades quilombolas e conservação da biodiversidade: o exemplo do Vale do Ribeira/SP. 2017.197 p. Tese (Doutorado em Direito Político e Econômico) - Universidade Presbiteriana Mackenzie, São Paulo-SP, 2017.

TEIXEIRA, G. M.; FIGUEIREDO, P. H. A.; FERRAZ, S. F. B.; SALEMI, L. F.; RANZINI, M.; RIZZI, N. E. Análise de classificadores de estágios sucessionais em um fragmento de Mata Atlântica. BIOFIX Scientific Journal, v. 4, n. 2, p. 88-96, 2019.

TORRES, D. R. 2011.96 p. Análise Multitemporal do Uso da Terra e Cobertura Florestal com Dados dos Satélites Landsat e Alos. Dissertação (Mestrado em Engenharia Florestal) - Universidade Federal de Santa Maria, Santa Maria - RS, 2011.

\section{Biografia do autor principal}

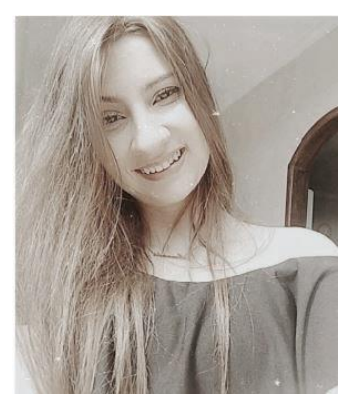

Amanda Lopes Maciel, natural de Ubá, Minas Gerais, nascida em 20 de março de 1995. Mestra em Sensoriamento Remoto pelo Instituto Nacional de Pesquisas Espaciais (INPE). Pós-graduada em Engenharia de Segurança do Trabalho e Graduada em Engenharia Ambiental na Universidade Federal de Itajubá - UNIFEI. Ex-Integrante do Programa de Educação Tutorial (PET- Ambiental) e possui experiências nas áreas de Licenciamento Ambiental e Geoprocessamento.

Esta obra está licenciada com uma Licença Creative Commons Atribuição 4.0 Internacional - CC BY. Esta licença permite que outros distribuam, remixem, adaptem e criem a partir do seu trabalho, mesmo para fins comerciais, desde que lhe atribuam o devido crédito pela criação original. 